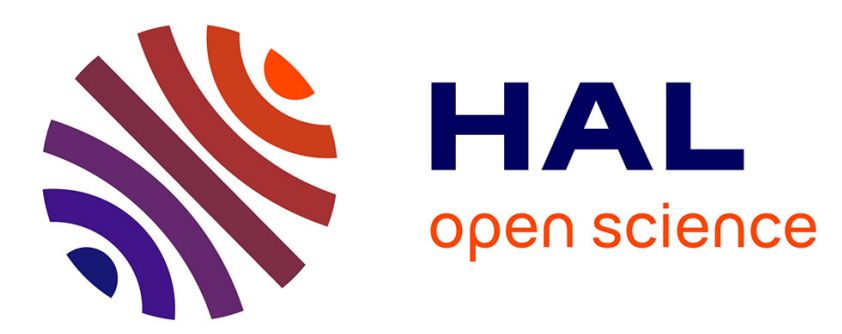

\title{
Experimental and numerical study of a shock-absorbing structure
}

\author{
Eric Dimnet, Elisabeth Haza Rozier, Gratien Vinceslas, Roberto Leon,
} Gonzalo Hernandez

\section{- To cite this version:}

Eric Dimnet, Elisabeth Haza Rozier, Gratien Vinceslas, Roberto Leon, Gonzalo Hernandez. Experimental and numerical study of a shock-absorbing structure. Acta Mechanica, 2013, 707, 23p. 10.1007/s00707-013-0900-8 . hal-00845998

\section{HAL Id: hal-00845998 \\ https://hal.science/hal-00845998}

Submitted on 18 Jul 2013

HAL is a multi-disciplinary open access archive for the deposit and dissemination of scientific research documents, whether they are published or not. The documents may come from teaching and research institutions in France or abroad, or from public or private research centers.
L'archive ouverte pluridisciplinaire HAL, est destinée au dépôt et à la diffusion de documents scientifiques de niveau recherche, publiés ou non, émanant des établissements d'enseignement et de recherche français ou étrangers, des laboratoires publics ou privés. 


\title{
Experimental and numerical study of a shock- absorbing structure
}

\author{
$\underset{c, e}{\text { Eric Dimnet }}{ }^{a}$, Elizabeth Haza-Rozier ${ }^{f}$, Gratien Vinceslas ${ }^{f}$, Roberto León ${ }^{c, d}$, Gonzalo Hernández \\ ${ }^{a}$ Design of Geotechnical Structures Group, IFSTTAR - Université Paris-Est \\ 58, Boulevard Lefebvre 75735 - Paris cedex 15 - FRANCE \\ ${ }^{c}$ Centro Científico Tecnológico CCTVal - Universidad Técnica Federico Santa María \\ ${ }^{d}$ Departamento de Informática - Universidad Técnica Federico Santa María \\ Av. España 1680 - Valparaíso - CHILE \\ ${ }^{e}$ Escuela de Ingeniería Industrial - Universidad de Valparaíso \\ Las Heras 6 - Valparaíso - CHILE \\ ${ }^{f}$ CER/DERDI/CETE Normandie Centre - Rouen - FRANCE
}

Keywords: Contact dynamics, computational method, granular media, impact.

\begin{abstract}
The purpose of this paper is to investigate the mechanical behavior of a sandwich structure impacted by a steel ball. Sandwich structures are used as protection devices against rock falls and made of a front wall of gabions and an inside layer of sand. Such a structure has been built, instrumented and experimentally tested using a pendular impact facility. A granular mechanical model of the structure is presented as well as the $\mathrm{A}-\mathrm{CD}^{2}$ (Atomized efforts Contact Dynamics respecting Clausius - Duhem's inequality) computational method for multi-body dynamics used to compute the impacts on the mechanical model. For four successive impacts with increasing energy level, the measured forces, accelerations and displacement in different locations of the structure are compared to the data obtained by the numerical simulations. The accuracy of the numerical results obtained in this study is encouraging for the use of this computational method in further simulations of impacts on granular layers with increased number of grains. However, some computational improvements need to be investigated to reduce the computational time.
\end{abstract}

\section{Introduction}

The design of protection devices against impacts of rocks is an important topic for engineers involved in protection strategies against rock falls as well as for researchers trying to understand and to model the resistance of the protection devices. Engineers use to design protection devices by empirical approaches or recommendations based on equivalent static solicitations. Hence, many experimental and numerical researches are carried out for understanding the mechanical phenomena involved during an impact and for improving the rules used to design of the protection devices [7, 20].

In this study, we focus on a type of protection devices named "sandwich structures" [12], which are made of a the juxtaposition of a front wall of gabions, that is to be impacted by the block, and of a nucleus, or inside layer, of a more deformable matter (in our case, sand) (Figure 1 - 2), which is designed to dissipate the impact energy in an optimized way.

The sandwich structure was studied both experimentally and numerically. The experimental impacts have been realized using a pendular impact device designed by CER (Experimental and research center in Rouen) (Figure 1 - 2) whereas the numerical simulations have been performed at IFSTTAR with the code STTAR3D using the $\mathrm{A}-\mathrm{CD}^{2}$ method $[1,21]$. 


\section{Experimental testing of the structure}

\section{Description of the impact station}

The facility used to perform the experimental impacts is a pendulum system, designed and built by CER for the purpose of performing experimental impacts on structures. It is a metallic structure which enables to swing steel ball $(254[\mathrm{~mm}]$ of diameter, $260[\mathrm{~kg}]$ of weight), maintained by two slings, in order to make it impact the tested structure with horizontal speed.

The ball is lifted to a chosen elevation thanks to a winch and a steel cable fixed to the backside of the ball. The maximum dropping height allowed by the facility is $4[\mathrm{~m}]$, corresponding to a $10[\mathrm{~kJ}]$ impact energy named $\mathrm{E}_{\max }$.

A 3[m] high wall has been built in reinforced concrete and stabilized by a compacted embankment in order to maintain the tested structures during the impacts and to enable the measurement of the forces generated by the impact at several positions on the backside of the structure (Figure 1).

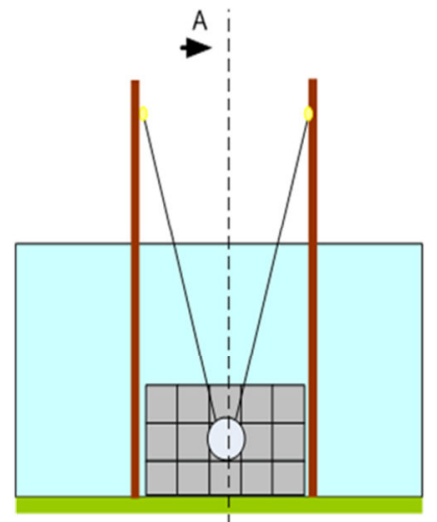

$A^{\prime}$
$\rightarrow !$

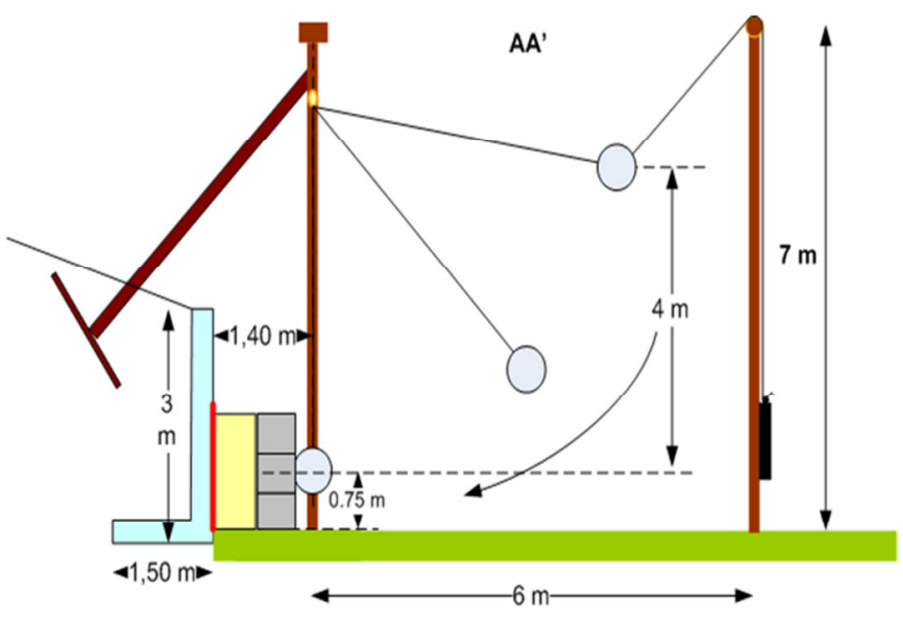

Figure 1 CER's pendular impact facility.

\section{Impacted structure}

The tested structure consists of a front wall of nine gabions and a sand nucleus. The cubic gabions $(0.5[\mathrm{~m}] \times 0.5[\mathrm{~m}] \times 0.5[\mathrm{~m}])$ are made of limestone blocks confined by a steel wire net. Each gabion consists of about 216 blocks.

A column of gabions is added on each side of this front wall in order to maintain and stabilize it during the impact.

The nucleus is made of Seine's sand, D1 classified with $\mathrm{w}=7.9 \%, \gamma_{\mathrm{h}}=18\left[\mathrm{kN} / \mathrm{m}^{3}\right][9]$.

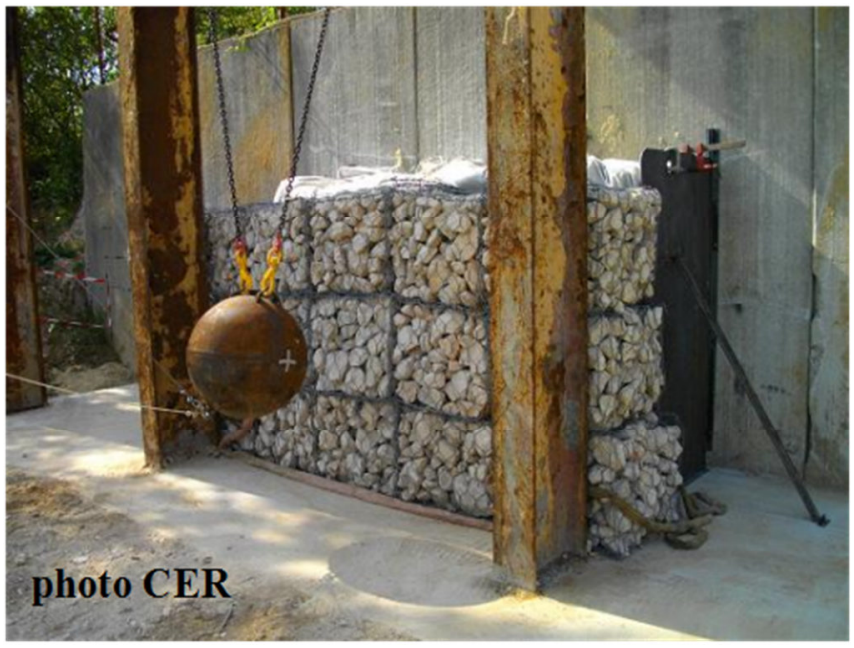

Figure 2 Tested sandwich structure. 


\section{Instrumentation}

The impacted structure is instrumented with sensors measuring accelerations, forces and displacements during the impact (Figure 3).

Accelerometers are used to measure the acceleration of the ball (Figure 4.a) and the acceleration of some of the blocks inside the gabions (Figure 4.b). For this purpose, "artificial" blocks made of concrete and instrumented with accelerometers are installed inside the gabions (Figure 4.b).

A steel plate containing 4 strain sensors is located vertically between the backside of the nucleus and the concrete wall in order to measure the forces generated by the impacts on the backside of the nucleus [13].

Additionally, a displacement sensor is placed between the steel plate and the back of the central gabion in order to measure the displacement of the gabion-wall during the impact (Figure 4.c).

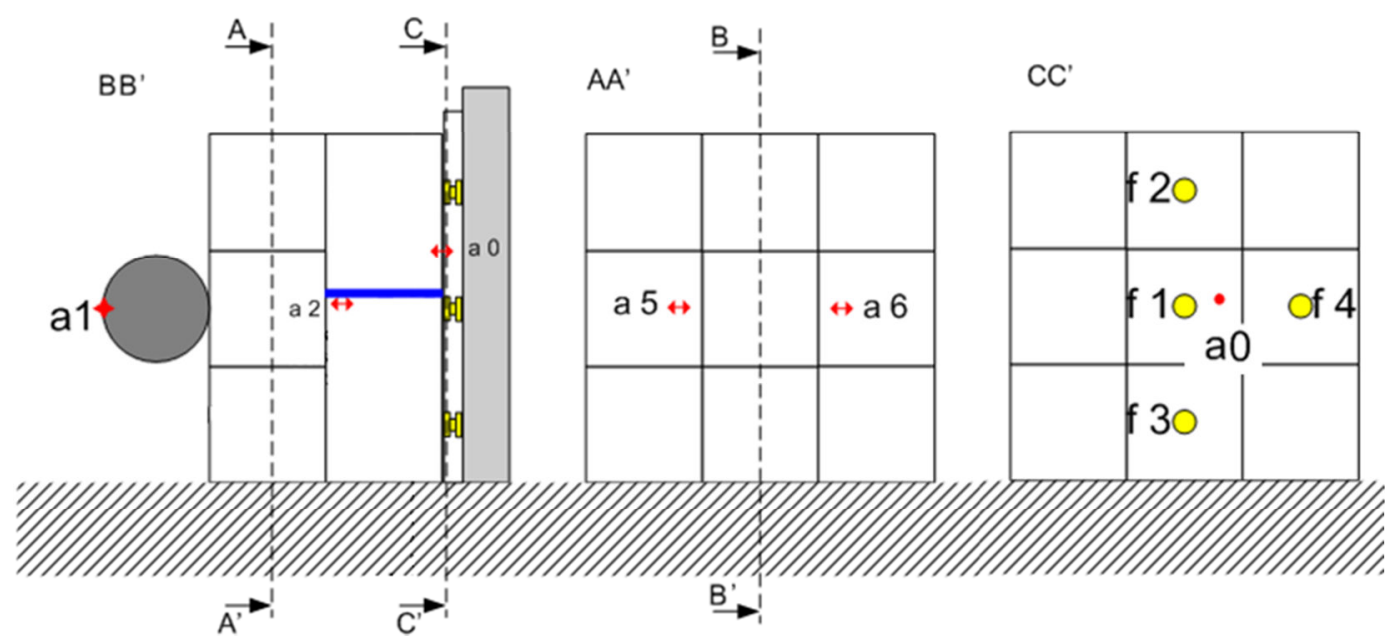

Figure 3 Instrumentation of the structure (a: accelerometers, f: force sensors).

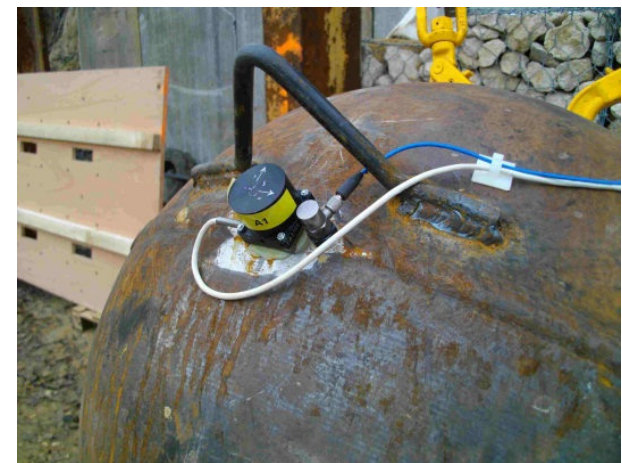

(a)

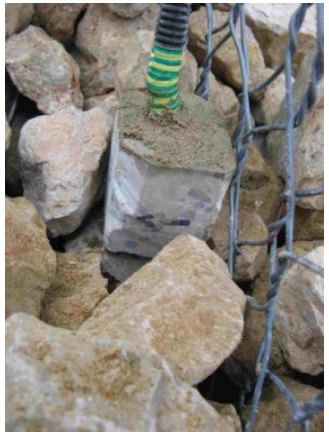

(b)

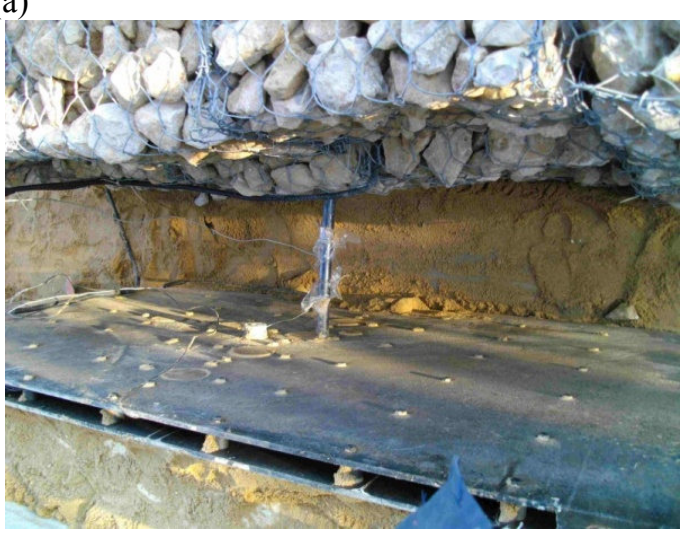

(c)

Figure 4 (a) Accelerometer on the iron ball. (b) Accelerometer inside a gabion. (c) Displacement sensor. 
The sandwich structure was impacted four times with increasing energy $(20 \%, 40 \%, 80 \%$ and $100 \%$ of $\left.\mathrm{E}_{\max }\right)$.

During each impact, the data of all the sensors were recorded simultaneously and the signals were processed by a second order Butterworth filter with a cut frequency of $600[\mathrm{~Hz}]$ [14].

\section{Mechanical model of the structure and numerical method for the computations of impacts}

The mechanical complexity of the tested structures makes some assumptions necessary for the numerical simulation of the impacts. The impacted structure is regarded as a granular media (the gabion - wall) with unilateral boundary conditions at its bottom and at both lateral sides, elastic boundary conditions for its contacts with the sand nucleus and "internal" elastic forces due to the confinement by the steel wire net surrounding the gabions.

Thus, the mechanical modeling of the structure requires to create a tridimensional granular media representing the collection of limestone blocks (or grains) of the gabion-wall, to model the interaction of these "grains" with the sand nucleus and the steel wire nettings and to compute the impact of the steel ball by taking into account the unilateral contact boundary conditions between grains, grains and steel ball as well as between grains and the bottom and lateral sides of the gabion-wall.

As the computation to perform is the impact of a rigid ball into a multi-body system with unilateral contacts and elastic boundary conditions, the code STTAR3D, developed at IFSTTAR for the numerical modeling of multi-body dynamics with unilateral contacts and based on the $\mathrm{A}-\mathrm{CD}^{2}$ method $[1,21]$ is used.

\section{Mechanical model}

The gabion-wall of the sandwich structure is modeled by a granular media in which each limestone block is a polyhedral grain. The grains are assumed rigid and no cracking model is taken into account. Thus, the contacts between the grains are the only sources of dissipation in the model. The action of the steel wire net is modeled by a confinement force applied to the grains belonging to the boundary of each gabion. The sand nucleus is modeled as a Winkler - Westergard solid [2] in contact with the grains of the backside of the gabion-wall.

In order to represent the geometry of the limestone blocks of the gabion, a 12 - sides polyhedral shape is used (Figure 5).



Figure 5 Shape of the grains.

Each gabion consists of an average number of 216 blocks. A sample of blocks was measured to obtain the values of $a, b, c$ and $d$ to use for modeling them as described in Figure 5 . The average values of these parameters are $7.8[\mathrm{~cm}]$ for $\mathrm{a}, 5.3[\mathrm{~cm}]$ for $\mathrm{b}, 6.5[\mathrm{~cm}]$ for $\mathrm{c}$ and $3.8[\mathrm{~cm}]$ for $\mathrm{d}$ with a dispersion of $23 \%$.

Thus, in order to make a numerical gabion, 216 grains of dimensions a, b, c and d randomly chosen within the range of $+/-23 \%$ of their average values, are randomly disposed and oriented inside a $0.5[\mathrm{~m}] \times 0.5[\mathrm{~m}] \times 0.5[\mathrm{~m}]$ box, following the algorithm recommended in [8]. This 
collection of grains is then compacted by numerical simulation until the containing box reaches the dimensions of the actual gabions, $0.5[\mathrm{~m}] \times 0.5[\mathrm{~m}] \times 0.5[\mathrm{~m}]$ (Figure 6). The numerical compaction is done by applying, to each side of the box, inwards percussion on each grain in contact with any side of the box. The numerical compactions have been performed using the $\mathrm{A}-\mathrm{CD}^{2}$ method.

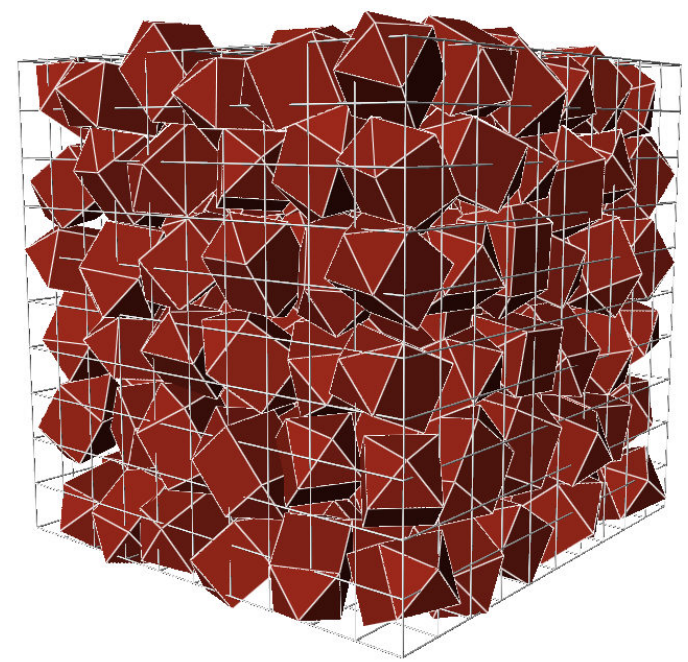

Figure 6 Gabion with 216 grains.

Nine different "numerical" gabions were computed this way. The grid drawn on Figure 6 represents the $0.5[\mathrm{~m}] \times 0.5[\mathrm{~m}] \times 0.5[\mathrm{~m}]$ dimensions of a gabion.

The steel wire net surrounding a gabion and insuring its confinement is then modeled by a force applied to each grain having a part of itself outside the $0.5[\mathrm{~m}] \times 0.5[\mathrm{~m}] \times 0.5[\mathrm{~m}]$ gabion and proportional to the volume of the grain that is outside this domain (Figure 7).
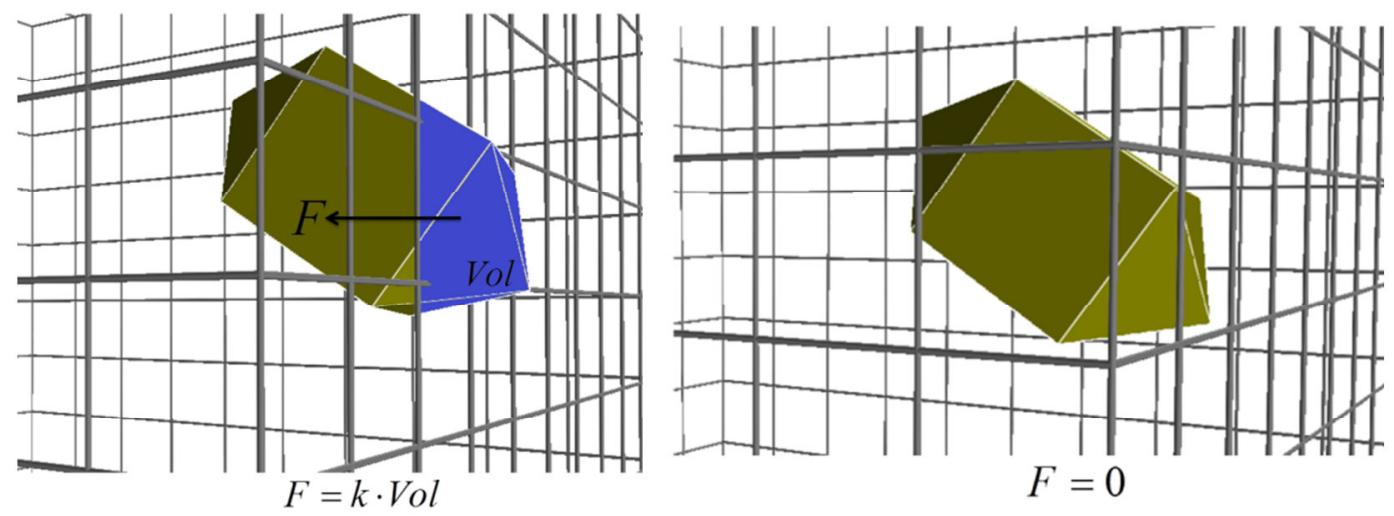

Figure 7 The force applied to the grain is proportional to the part of its volume outside the boundary of the gabion (left); it is null if the grain is inside of the gabion (right).

The use of $\mathrm{k}=10^{11}\left[\mathrm{~N} / \mathrm{m}^{3}\right]$ allowed to obtain nine size - and shape - stabilized numerical gabions which are placed like in the experimental structure, in order to build the gabion - wall.

We thus obtain a system of 1944 polyhedral grains in unilateral contact and submitted to elastic confinement forces at the boundary of the gabions. Let us precise that a grain from the boundary of a gabion thus is submitted to the confinement force (if a part of it crosses the boundary of the gabion he belongs to), to contact forces due to its contacts with grains of the gabion he belongs to, but now also to contact forces due to its contacts with grains from the neighbor gabion. 

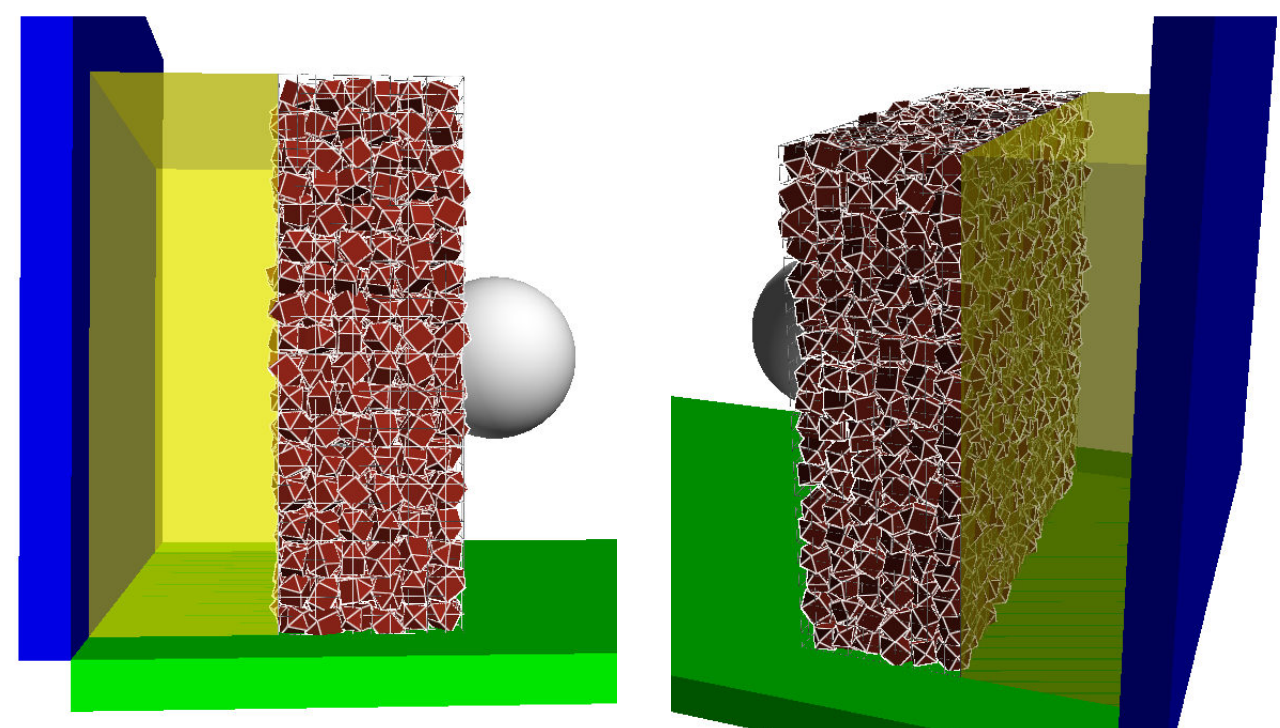

Figure 8 The initial position of the ball and the 9 gabions. The transparent yellow region is the volume of the sand.

\section{Boundary conditions}

As the experimental impacts do not show any significant displacement of the two extra columns of gabions disposed at each lateral side of the nine gabions wall in order to stabilize it (Figure 9), they are not modeled by a collection of grains, but by unilateral contact boundary conditions for the grains. Unilateral contact boundary conditions are also applied to the grains of the bottom of the wall to model the interaction with the soil.

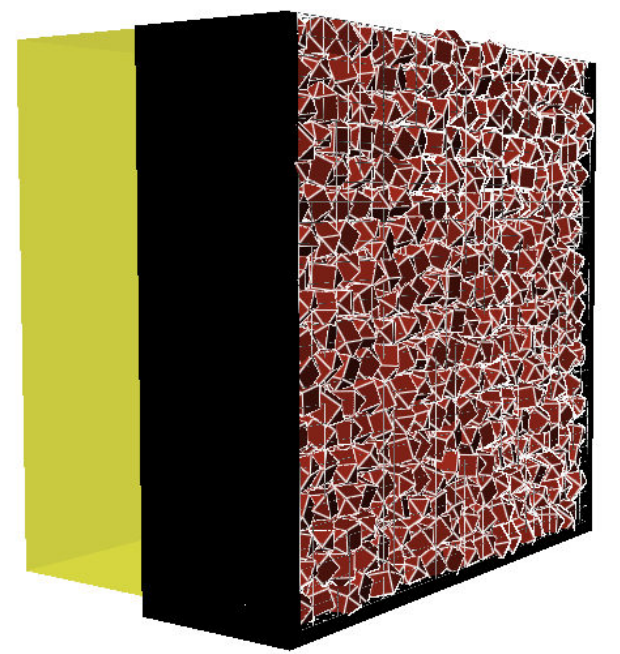

Figure 9 The unilateral boundary condition (black zone).

The backside of the gabion wall is in contact with the nucleus of the structure, its most deformable part, made of sand and backed on to a rigid concrete wall. Experimental measurements of Yong's modulus of the used sand have values around $300[\mathrm{MPa}](+/-7 \%)$. This part of the structure is modeled by a Winkler - Westergaard (Figure 10) elastic solid [2] in the direction of the impact. In this direction, a displacement $\Delta \mathrm{z}$ corresponds to an elastic force $\mathrm{F}=\mathrm{k}_{\mathrm{ww}} \Delta \mathrm{z}$.

This boundary condition is to be applied to each grain of the backside of the gabion wall during the impact. According to the measurements of Young's modulus of the sand, $\mathrm{k}_{\mathrm{ww}}$ is set to $3 \times 10^{4}[\mathrm{~N} / \mathrm{m}]$. 


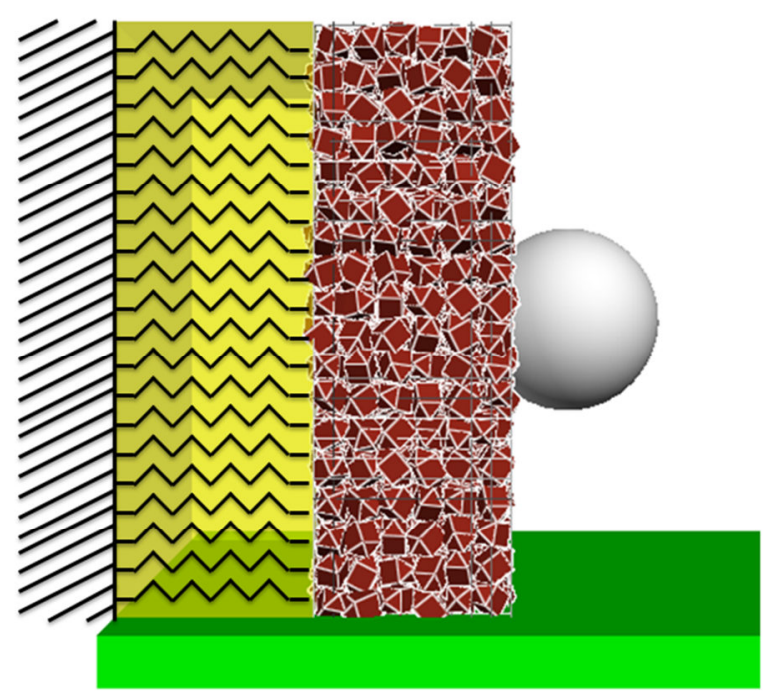

Figure 10 Winkler - Westergaard boundary condition.

\section{Numerical model and computational method}

The A-CD ${ }^{2}$ computational method has been developed at IFSTTAR for the purpose of the computation of 3D polyhedral granular media dynamics $[3,15,16,21]$.

As in the non - smooth Contact Dynamics method [4], the grains are in unilateral contact. The A$\mathrm{CD}^{2}$ method uses a different way of expressing the contact forces, having for consequence a different formulation of the equations to solve at each time step.

The basic assumption made about the evolution of the multi - body system is, that the solids have constant velocities inside the discrete time intervals and instantaneous velocity jumps at the boundaries of theses intervals.

The first consequence is that the forces are concentrated in time; they are then called percussions and are applied to the solids at the instants of velocity jumps (boundaries of the discrete time intervals).

The second consequence is that two categories of forces must be distinguished: the forces depending of the velocities and the ones that do not.

For the numerical simulation of the impact on the mechanical model of the sandwich structure, the forces not depending on the velocities are the gravity force and the elastic forces applied to the grains by the Winkler - Westergaard [2] solid and the steel wire netting. The gravity force does not depend on the positions and its expression is easy to get for any grain. The mentioned elastic forces depend on the positions and therefore need to be computed taking into account the positions of the grains. The $\mathrm{A}-\mathrm{CD}^{2}$ method considers the positions of the grains at the instant of velocity jump to compute these forces. According to the positions of the grains at this instant, these forces $\vec{f}$ $f$ are computed using the laws mentioned above. They are to be applied to the grains at the instants of time discontinuity, under the form of a percussion of magnitude

$$
\vec{P}^{e x}=\vec{f} \cdot \Delta t
$$

The time step for the computation is $\Delta \mathrm{t}$ and the percussion is $\vec{P}^{e x}$, pointing out the fact that it is independent from the velocities and therefore will be considered as "explicit" in the equations to solve for the velocity jumps.

The forces depending on the velocities are contact forces. Their expression at the instants of velocity jumps involves the left and right limits, $U^{-}$and $U^{+}$, of the velocities. The left limit of the velocities is known at this instant, which is the right hand side boundary of the interval inside which the velocities are considered constant.

Thus, as the percussions corresponding to forces not depending of velocities are known (they are explicit percussions), the formulation of the contact percussions as functions of $U^{-}$and $U^{+}$, together with the balance of momentum equations, lead to an system of equations enabling to compute the right limits of the velocities $U^{+}$and to move on for the next time step. 
Let us mention that the contacts between the grains must be computed previous to solving the equations, as the contact forces appear in the equation under the form of percussions applied to the corresponding contact points. The contact points are computed by taking into account the positions of the solids at the instant of velocity jumps.

One can summarize the method by the following three recursive steps:

1. The solids move with constant velocity during $\Delta \mathrm{t}$.

2. The contacts are computed with the positions of the solids and the end of the time step.

3. The new velocities are computed; they replace the previous ones in step 1 .

\section{Equations for velocity jumps}

As the problem to solve at step 3 is an instantaneous velocity discontinuity, an instantaneous collision model is used to describe the velocity jumps. For the sake of simplicity, the model is first exposed for a single point colliding to a rigid fixed surface and having an instantaneous velocity discontinuity, before generalizing the formulation to a simultaneous collision of $\mathrm{N}$ rigid solids [5, 17].

\section{Instantaneous collision model}

As the collision is assumed instantaneous, the velocity $\vec{U}$ of the point is discontinuous at the instant of the collision, having a left and right limit noted $\vec{U}^{-}$and $\vec{U}^{+}$. The contact force is concentrated in time, becoming a percussion noted $\vec{P}^{\text {int }}[5]$.

One can also take into account an explicit percussion $\vec{P}^{e x}$, not depending on $\vec{U}$, also applied to the point at the instant of collision. This explicit percussion is later used to take into account the forces not depending on the velocities in the equations of the velocity jumps.

Under these assumptions the balance of momentum equation for the point with mass $m$ is

$$
m\left(\vec{U}^{+}-\vec{U}^{-}\right)=-\vec{P}^{\text {int }}+\vec{P}^{e x}
$$

The equation (2) proves the existence of a duality in the sense of internal work between $\vec{P}^{\text {int }}$ and $\frac{\vec{U}^{+}-\vec{U}^{-}}{2}$. Therefore the constitutive laws describing the mechanical interactions between the point and the rigid surface during the collision are formulated by expressing $\vec{P}^{\text {int }}$ as a function of $\frac{\vec{U}^{+}-\vec{U}^{-}}{2}[18]$

\section{Constitutive laws}

Constitutive laws have to model the contact interactions during the collision in a way that makes sure that the collision is dissipative and that the point does not penetrate the rigid surface. These two conditions are made explicit by splitting the internal percussion into a dissipative percussion $\vec{P}^{d}$, modeling the dissipative interaction during the collision and a reactive percussion $\vec{P}^{\text {reac }}$ insuring the non-interpenetration, which can as well be considered as the reaction to the non interpenetration condition $\vec{U}^{+} \cdot \vec{N} \geq 0$ :

$$
\vec{P}^{\text {int }}=\vec{P}^{d}+\vec{P}^{r e a c}
$$

The dissipative percussion is formulated using a pseudo - potential of dissipation $\Phi^{d}$, which is a convex, positive function and null at the origin [18]:

$$
\vec{P}^{d} \in \partial \Phi^{d}\left(\frac{\vec{U}^{-}+\vec{U}^{+}}{2}\right)
$$


The reactive percussion, reaction to the non-interpenetration condition, is formulated using the indicator functions $I_{K}[5,18,21]$ :

$$
\vec{P}^{r e a c} \in \partial I_{K}\left(\frac{\vec{U}^{-}+\vec{U}^{+}}{2}\right) \cdot \vec{N}, \quad K=\left[\frac{\vec{U}^{-} \cdot \vec{N}}{2}, \infty[\right.
$$

As $K$ is convex and contains the value 0 , the indicator function $I_{K}$ is a pseudo - potential of dissipation [18] and the internal percussion can be written

$$
\vec{P}^{\mathrm{int}} \in \partial \Phi\left(\frac{\vec{U}^{-}+\vec{U}^{+}}{2}\right), \quad \Phi=\Phi^{d}+I_{K}
$$

As it is a sum of pseudo - potential of dissipation, $\Phi$ is also a pseudo - potential of dissipation. This enables to prove the existence and uniqueness of $\vec{U}^{+}$as well as the fact that the collision is always dissipative.

\section{Simultaneous collision of $\mathbf{N}$ solids with explicit percussions resulting from forces not depending on velocities}

According to the assumptions made above about the evolution of the system, especially the solids moving with constant velocities during $\Delta \mathrm{t}$, the problem to solve at an instant of velocity jump has to be considered as a simultaneous collision of several solids. Indeed all the contacts occurring during $\Delta \mathrm{t}$ are considered to occur at the instant of velocity jump as they are computed according to the positions of the solids at this instant. The problem to solve thus becomes similar to an instantaneous collision of several solids with known velocities before the collision.

Therefore, the instantaneous collision model exposed above for a point has to be generalized for $\mathrm{N}$ colliding bodies with mass $m_{i}$, center of gravity $G_{i}$, and an internal tensor $I_{i}$.

The set of contacts points among solid $i$ and solid $j$ is denoted by $S_{i j}$. These contacts among solids are assumed to be punctual. The $k^{\text {th }}$ contact among solid $i$ and solid $j$ takes place at point $\vec{A}_{i j k}$ and $\vec{P}_{i j k}^{\text {int }}$ is the contact percussion at this point.

The set of points where explicit percussions are applied to solid $i$ is denoted by $S_{i}^{\prime}$. The percussion $\vec{P}_{i l}^{e x}$ is applied to the $l^{\text {th }}$ point of this set noted $\vec{B}_{i l}$.

The velocity of the center of gravity $G_{i}$ is denoted by $\vec{U}_{i}$ and the rotational velocity by $\vec{\Omega}_{i}$ of solid $i$ and define the vector $\hat{U}=\left[\ldots, \vec{U}_{i}, \vec{\Omega}_{i}, \ldots\right]$.

With these definitions, the relative velocity of solids $i$ and $j$ at their contact point $\vec{A}_{i j k}$ is given by

$$
\vec{D}_{i j}\left(\hat{U}, \vec{A}_{i j k}\right)=\left(\vec{U}_{i}+\vec{\Omega}_{i} \times{\overrightarrow{G_{i} A_{i j k}}}\right)-\left(\vec{U}_{j}+\vec{\Omega}_{j} \times{\overrightarrow{G_{j} A_{i j k}}}\right)
$$

And at point $\vec{B}_{i l}$ the velocity of solid $i$ is

$$
\vec{E}_{i}\left(\hat{U}, \vec{B}_{i l}\right)=\left(\vec{U}_{i}+\vec{\Omega}_{i} \times \overrightarrow{G_{i} B_{i l}}\right)
$$

Let $\hat{V}=\left[\ldots, \vec{V}_{i}, \vec{\omega}_{i}, \ldots\right]$ be the virtual velocities vector. The virtual work of the acceleration forces is 


$$
\begin{array}{r}
W^{a c c}(\hat{V}-\hat{U})=\sum_{i=1}^{N} m_{i}\left(\vec{U}_{i}^{+}-\vec{U}_{i}^{-}\right)\left(\frac{\vec{V}_{i}^{-}+\vec{V}_{i}^{+}}{2}-\frac{\vec{U}_{i}^{-}+\vec{U}_{i}^{+}}{2}\right)+ \\
I_{i}\left(\vec{\Omega}_{i}^{+}-\vec{\Omega}_{i}^{-}\right)\left(\frac{\vec{\omega}_{i}^{-}+\vec{\omega}_{i}^{+}}{2}-\frac{\vec{\Omega}_{i}^{-}+\vec{\Omega}_{i}^{+}}{2}\right)
\end{array}
$$

The virtual work of contact forces is

$$
\begin{gathered}
W^{\mathrm{int}}(\hat{V}-\hat{U})=-\sum_{i=1}^{N-1} \sum_{j=i+1}^{N} \sum_{\vec{A}_{i j k} \in S_{i j}} \vec{P}_{i j k}^{\mathrm{int}}\left(\frac{\vec{D}_{i j}\left(\hat{V}^{+}, \vec{A}_{i j k}\right)+\vec{D}_{i j}\left(\hat{V}^{-}, \vec{A}_{i j k}\right)}{2}\right) \\
-\vec{P}_{i j k}^{\mathrm{int}}\left(\frac{\vec{D}_{i j}\left(\hat{U}^{+}, \vec{A}_{i j k}\right)+\vec{D}_{i j}\left(\hat{U}^{-}, \vec{A}_{i j k}\right)}{2}\right)
\end{gathered}
$$

The virtual work of the explicit forces is

$$
\begin{aligned}
W^{e x}(\hat{V}-\hat{U})=\sum_{i=1}^{N} & \sum_{\vec{B}_{i l} \in S_{i}^{\prime}} \vec{P}_{i l}^{e x}\left(\frac{\vec{E}_{i}\left(\hat{V}^{+}, \vec{B}_{i l}\right)+\vec{E}_{i}\left(\hat{V}^{-}, \vec{B}_{i l}\right)}{2}\right) \\
& -\vec{P}_{i l}^{e x}\left(\frac{\vec{E}_{i}\left(\hat{U}^{+}, \vec{B}_{i l}\right)+\vec{E}_{i}\left(\hat{U}^{-}, \vec{B}_{i l}\right)}{2}\right)
\end{aligned}
$$

And the principle of virtual work implies that for any $\hat{V}$

$$
\begin{aligned}
& \sum_{i=1}^{N} m_{i}\left(\vec{U}_{i}^{+}-\vec{U}_{i}^{-}\right)\left(\frac{\vec{V}_{i}^{-}+\vec{V}_{i}^{+}}{2}-\frac{\vec{U}_{i}^{-}+\vec{U}_{i}^{+}}{2}\right)+I_{i}\left(\vec{\Omega}_{i}^{+}-\vec{\Omega}_{i}^{-}\right)\left(\frac{\vec{\omega}_{i}^{-}+\vec{\omega}_{i}^{+}}{2}-\frac{\vec{\Omega}_{i}^{-}+\vec{\Omega}_{i}^{+}}{2}\right)+ \\
& \sum_{i=1}^{N-1} \sum_{j=i+1}^{N} \sum_{\vec{A}_{i j k} \in S_{i j}} \vec{P}_{i j k}^{\mathrm{int}}\left(\frac{\vec{D}_{i j}\left(\hat{V}^{+}, \vec{A}_{i j k}\right)+\vec{D}_{i j}\left(\hat{V}^{-}, \vec{A}_{i j k}\right)}{2}\right)-\vec{P}_{i j k}^{\mathrm{int}}\left(\frac{\vec{D}_{i j}\left(\hat{U}^{+}, \vec{A}_{i j k}\right)+\vec{D}_{i j}\left(\hat{U}^{-}, \vec{A}_{i j k}\right)}{2}\right)= \\
& \sum_{i=1}^{N} \sum_{\vec{B}_{i l} \in S_{i}^{\prime}} \vec{P}_{i l}^{e x}\left(\frac{\vec{E}_{i}\left(\hat{V}^{+}, \vec{B}_{i l}\right)+\vec{E}_{i}\left(\hat{V}^{-}, \vec{B}_{i l}\right)}{2}-\frac{\vec{E}_{i}\left(\hat{U}^{+}, \vec{B}_{i l}\right)+\vec{E}_{i}\left(\hat{U}^{-}, \vec{B}_{i l}\right)}{2}\right)
\end{aligned}
$$

Constitutive laws for the contact percussions are defined using pseudo - potentials defined by the same way as for (6)

$$
\vec{P}_{i j k}^{\mathrm{int}} \in \partial \Phi_{i j k}\left(\frac{\vec{D}_{i j}\left(\hat{U}^{+}, \vec{A}_{i j k}\right)+\vec{D}_{i j}\left(\hat{U}^{-}, \vec{A}_{i j k}\right)}{2}\right)
$$

Thus (12) becomes

$$
\begin{aligned}
& \sum_{i=1}^{N} m_{i}\left(\vec{U}_{i}^{+}-\vec{U}_{i}^{-}\right)\left(\frac{\vec{V}_{i}^{-}+\vec{V}_{i}^{+}}{2}-\frac{\vec{U}_{i}^{-}+\vec{U}_{i}^{+}}{2}\right)+I_{i}\left(\vec{\Omega}_{i}^{+}-\vec{\Omega}_{i}^{-}\left(\frac{\vec{\omega}_{i}^{-}+\vec{\omega}_{i}^{+}}{2}-\frac{\vec{\Omega}_{i}^{-}+\vec{\Omega}_{i}^{+}}{2}\right)+\right. \\
& \sum_{i=1}^{N-1} \sum_{j=i+1}^{N} \sum_{\vec{A}_{i j k} \in S_{i j}} \Phi_{i j k}\left(\frac{\vec{D}_{i j}\left(\hat{V}^{+}, \vec{A}_{i j k}\right)+\vec{D}_{i j}\left(\hat{V}^{-}, \vec{A}_{i j k}\right)}{2}\right)-\Phi_{i j k}\left(\frac{\vec{D}_{i j}\left(\hat{U}^{+}, \vec{A}_{i j k}\right)+\vec{D}_{i j}\left(\hat{U}^{-}, \vec{A}_{i j k}\right)}{2}\right)- \\
& \sum_{i=1}^{N} \sum_{\vec{B}_{i l} \in S_{i}^{\prime}} \vec{P}_{i l}^{e x}\left(\frac{\vec{E}_{i}\left(\hat{V}^{+}, \vec{B}_{i l}\right)+\vec{E}_{i}\left(\hat{V}^{-}, \vec{B}_{i l}\right)}{2}\right)-\vec{P}_{i l}^{e x}\left(\frac{\vec{E}_{i}\left(\hat{U}^{+}, \vec{B}_{i l}\right)+\vec{E}_{i}\left(\hat{U}^{-}, \vec{B}_{i l}\right)}{2}\right) \geq 0
\end{aligned}
$$


By introducing the scalar product

$$
\langle\hat{U} \mid \hat{V}\rangle=\sum_{i=1}^{N} m_{i} \vec{U}_{i} \cdot \vec{V}_{i}+I_{i} \vec{\Omega}_{i} \vec{\omega}_{i}
$$

Defining the vector $\hat{T}^{e x}$ such as

$$
\left\langle\hat{T}^{e x} \mid \hat{V}\right\rangle=\sum_{i=1}^{N} \sum_{\vec{B}_{i l} \in S_{i}^{\prime}} \vec{P}_{i l}^{e x} \cdot \vec{V}_{i}+\left(\vec{P}_{i l}^{e x} \times{\overrightarrow{B_{i l} G_{i}}}_{)} \cdot \vec{\omega}_{i}\right.
$$

And pseudo - potential $\Phi$ such as

$$
\Phi(\hat{V})=\sum_{i=1}^{N-1} \sum_{j=i+1}^{N} \sum_{A_{i j k} \in S_{i j}} \Phi_{i j k}\left(\vec{D}_{i j}\left(\hat{V}, \vec{A}_{i j k}\right)\right)
$$

Then (12) becomes

$$
\forall \hat{V},\left\langle\hat{U}^{+}-\hat{U}^{-}-\hat{T}^{e x} \mid \hat{V}-\frac{\hat{U}^{+}+\hat{U}^{-}}{2}\right\rangle+\Phi(\hat{V})-\Phi\left(\frac{\hat{U}^{+}+\hat{U}^{-}}{2}\right) \geq 0
$$

Given that $\mathfrak{R}^{6 N}$ has a scalar product defined by $\langle\cdot \mid \cdot\rangle$ and given the definition of sub - gradient, the formulation (18) is equivalent to the inclusion

$$
-\left(\hat{U}^{+}-\hat{U}^{-}-\hat{T}^{e x}\right) \in \partial \Phi\left(\frac{\hat{U}^{+}+\hat{U}^{-}}{2}\right)
$$

By noting $X=\frac{\hat{U}^{+}+\hat{U}^{-}}{2}$, it obtains

$$
2 \hat{U}^{-}+\hat{T}^{e x} \in 2 X+\partial \Phi(X)
$$

This inclusion is finally equivalent to the constrained minimization problem

$$
\begin{aligned}
& \inf _{X \in C}\langle X \mid X\rangle+\Phi^{d}(X)-\left\langle 2 \hat{U}^{-}+\hat{T}^{e x} \mid X\right\rangle \\
& C=\left\{X \in \mathfrak{R}^{6 N} \mid \phi_{l}(X) \leq 0, \quad l=1, p\right\}
\end{aligned}
$$

The function $\Phi^{d}$ is the sum of dissipative parts ((4) and (6)), the indicator function being replaced by the constraints $\phi_{l}(X)$ defining the set $C$. The variable $p$ is the total number of contacts. A contact index $l$ corresponding to the contact point $\vec{A}_{i j k}$, the corresponding constraint is

$$
\phi_{l}(X)=\left(\vec{D}_{i j}\left(\frac{\hat{U}}{2}, \vec{A}_{i j k}\right)-\vec{D}_{i j}\left(X, \vec{A}_{i j k}\right)\right) \cdot \vec{N}_{l}
$$

where $\vec{N}_{l}$ is the normal vector at contact point $\vec{A}_{i j k}$ pointing towards solid $i$. 


\section{Numerical method for the resolution of the velocity jumps}

The function $F(X)$ is defined by

$$
F(X)=\langle X \mid X\rangle+\Phi^{d}(X)-\left\langle 2 \hat{U}^{-}+\hat{T}^{e x} \mid X\right\rangle
$$

The problem to solve is a constrained minimization problem of $F(X)$. The solution is a saddle point of the Lagrange function [21]:

$$
L(X, \mu)=F(X)+\sum_{l=1}^{p} \mu_{l} \phi_{l}(X)
$$

One can prove the existence and uniqueness of $X^{*}$ and the existence of the Lagrange multipliers $\mu^{*}$ whereas the uniqueness of $\mu^{*}$ is only insured if the corresponding constraints are linearly independent [21].

The function $F(X)$ as well as the set $C$ being convex and the constraints being linear, the Uzawa method is used tom compute the saddle point $\left(X^{*}, \mu^{*}\right)$ of $L(X, \mu)$. From the computational point of view, the method consists in solving a succession of unconstrained minimization problem:

a) Let be $\mu_{0} \in \mathfrak{R}_{p}^{+}$the initial value for $\mu$.

b) Compute $X_{n}=\arg \min \left\{F(X)+\sum_{l=1}^{p} \mu_{l} \phi_{l}(X), \quad X \in \mathfrak{R}^{6 N}\right\}$.

c) Compute $\mu_{l}^{n+1}=\max \left\{0, \mu_{l}^{n}+\rho \phi_{l}\left(X_{n}\right)\right\}$.

d) Repeat from step (b) until a convergence condition is satisfied.

For the presented application, quadratic pseudo - potentials are used, making $\Phi^{d}(X)$ a quadratic function. Thus, $F(X)$ is quadratic and the conjugate gradient method is used with accuracy for computing step (b). It is applied to the stationary condition

$$
\nabla L\left(X_{n}, \mu_{n}\right)=\nabla F(X)+\sum_{l=1}^{p} \mu_{l} \nabla \phi_{l}\left(X_{n}\right)=0
$$

In step (c), the value of $\rho$ has to be carefully chosen to insure the convergence. Numerical analysis $[11,19]$ and numerical experimentations show that an efficient value is around the average mass of the grains in the present situation.

The resolution of the velocity jump problem enables to obtain the new velocities of all the solids in the system and, simultaneously, the contact forces, thanks to the constitutive laws and the Lagrange multipliers.

\section{Numerical computations and comparison with experimental results}

Similarly to the experimental testing of the structure, four successive impacts with increasing level of energy are computed with the mechanical model of the sandwich structure (Figure 11). The constitutive law used for the contact force between grains is

$$
\vec{P}^{d} \cdot \vec{N}=k_{N}\left(\frac{\vec{U}^{-}+\vec{U}^{+}}{2}\right) \cdot \vec{N}
$$


and

$$
\vec{P}^{d}-\left(\vec{P}^{d} \cdot \vec{N}\right) \cdot \vec{N}=k_{T}\left[\left(\left(\frac{\vec{U}^{-}+\vec{U}^{+}}{2}\right)-\left(\frac{\vec{U}^{-}+\vec{U}^{+}}{2}\right) \cdot \vec{N}\right) \cdot \vec{N}\right]
$$

with

$$
\begin{aligned}
& k_{N}=0.5 \times 10^{-3}\left[\frac{N s^{2}}{m}\right] \\
& k_{T}=0.3 \times 10^{-3}\left[\frac{N s^{2}}{m}\right]
\end{aligned}
$$

The time step used for the computation is $\Delta t=10^{-3}[s]$, making the friction force between grains a linear viscous force with a viscosity coefficient $v=0.3[\mathrm{Ns} / \mathrm{m}]$.

To cover the duration of the signals recorded during the experimental collisions, 100 time steps are computed for each collision. At each step, the number of contacts to take into account is between 6200 and 8600 in the system.

\begin{tabular}{|c|c|}
\hline Impact with $20 \%$ of $\mathrm{E}_{\max }$ & Impact with $40 \%$ of $\mathrm{E}_{\max }$ \\
\hline Impact with $80 \%$ of $\mathrm{E}_{\max }$ & Impact with $100 \%$ of $\mathrm{E}_{\max }$ \\
\hline & \\
\hline
\end{tabular}

Figure 11 Positions of the steel ball and the grains of the central gabion (the others have been skipped) after each one of the four computed impacts.

For each impact, forces, accelerations and displacements are computed in the mechanical model at the places where they have been measured during the experiment. Thus, we obtain the numerical signals to compare with the experimental ones for the validation of the model.

\section{Forces}

The forces are measured and computed at the positions $\mathrm{f} 1, \mathrm{f} 2, \mathrm{f} 3$ and $\mathrm{f} 4$ as shown in Figure 3 . The computation of the forces is made thanks to the deformation of the Winkler - Westergaard solid. In the Figure $12-15$ is shown the comparison of the experimental and numerical signals at each one of these spots for the four successive impacts of $20 \%, 40 \%, 80 \%$ and $100 \%$ of $\mathrm{E}_{\max }$. 


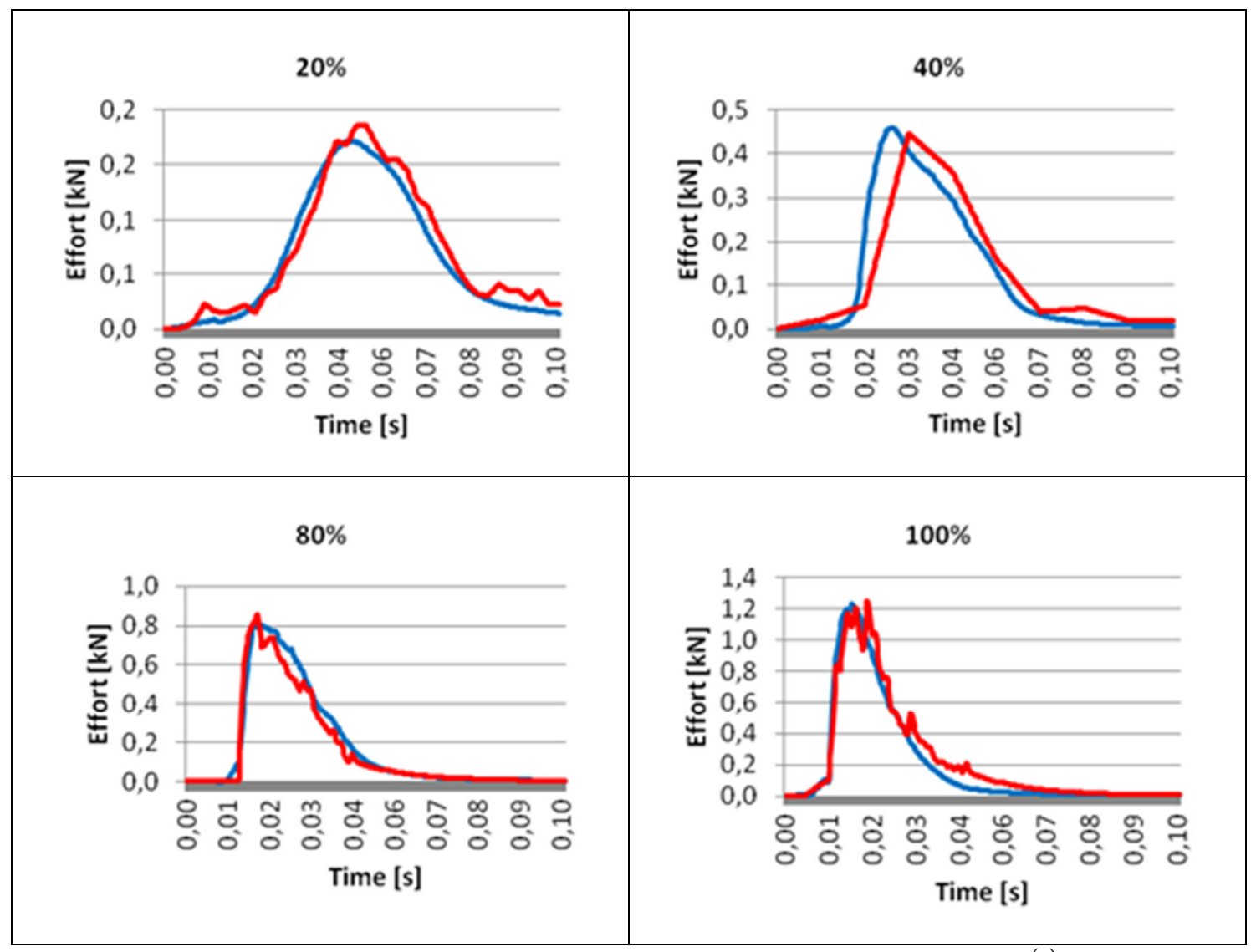

Figure 12 Comparison between experimental (blue) and numerical (red) signals $f_{1}(t)$ for the four impacts of $20 \%, 40 \%, 80 \%$ and $100 \%$ of $\mathrm{E}_{\max }$.

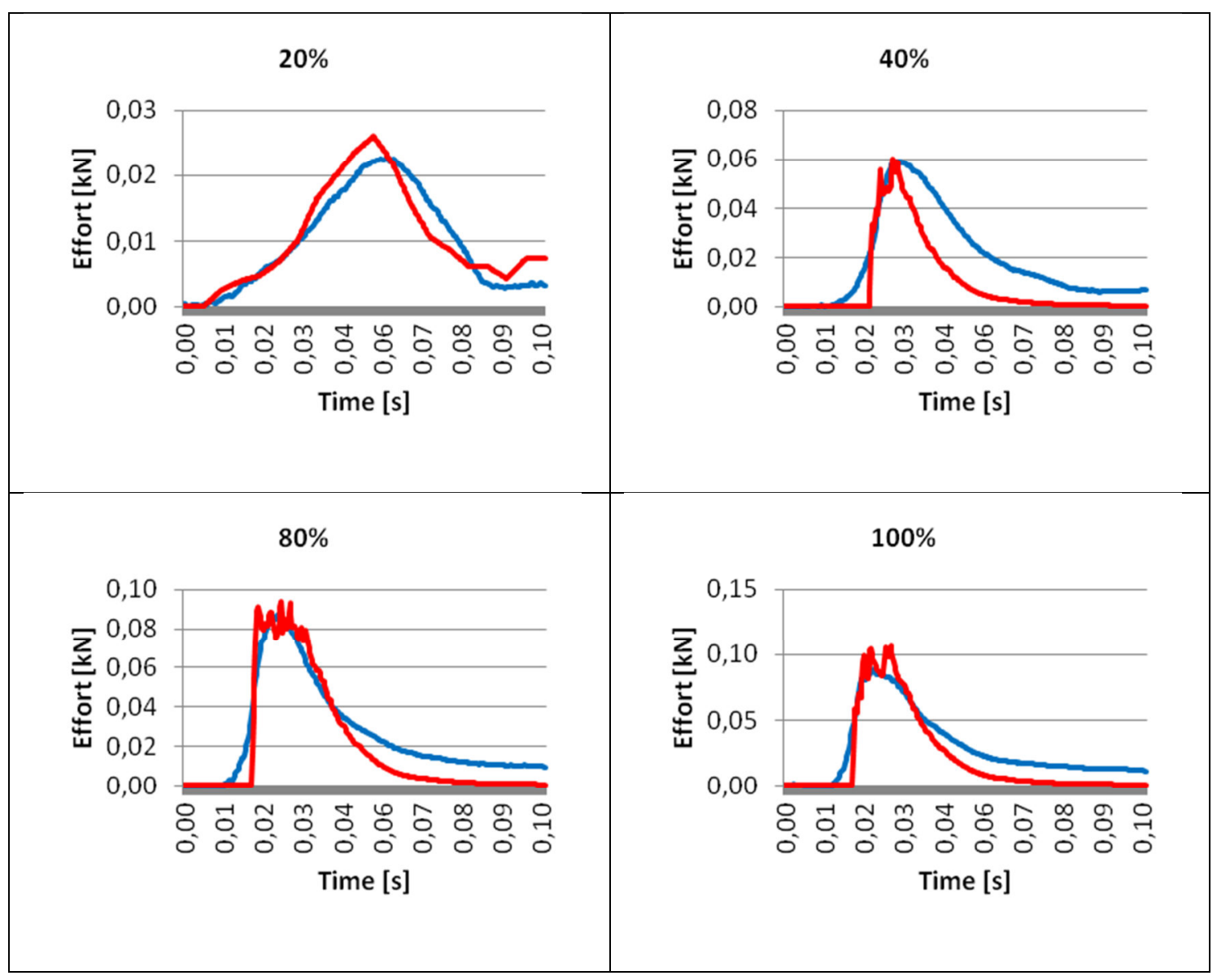


Figure 13 Comparison between experimental (blue) and numerical (red) signals $f_{2}(t)$ for the four impacts of $20 \%, 40 \%, 80 \%$ and $100 \%$ of $\mathrm{E}_{\max }$.

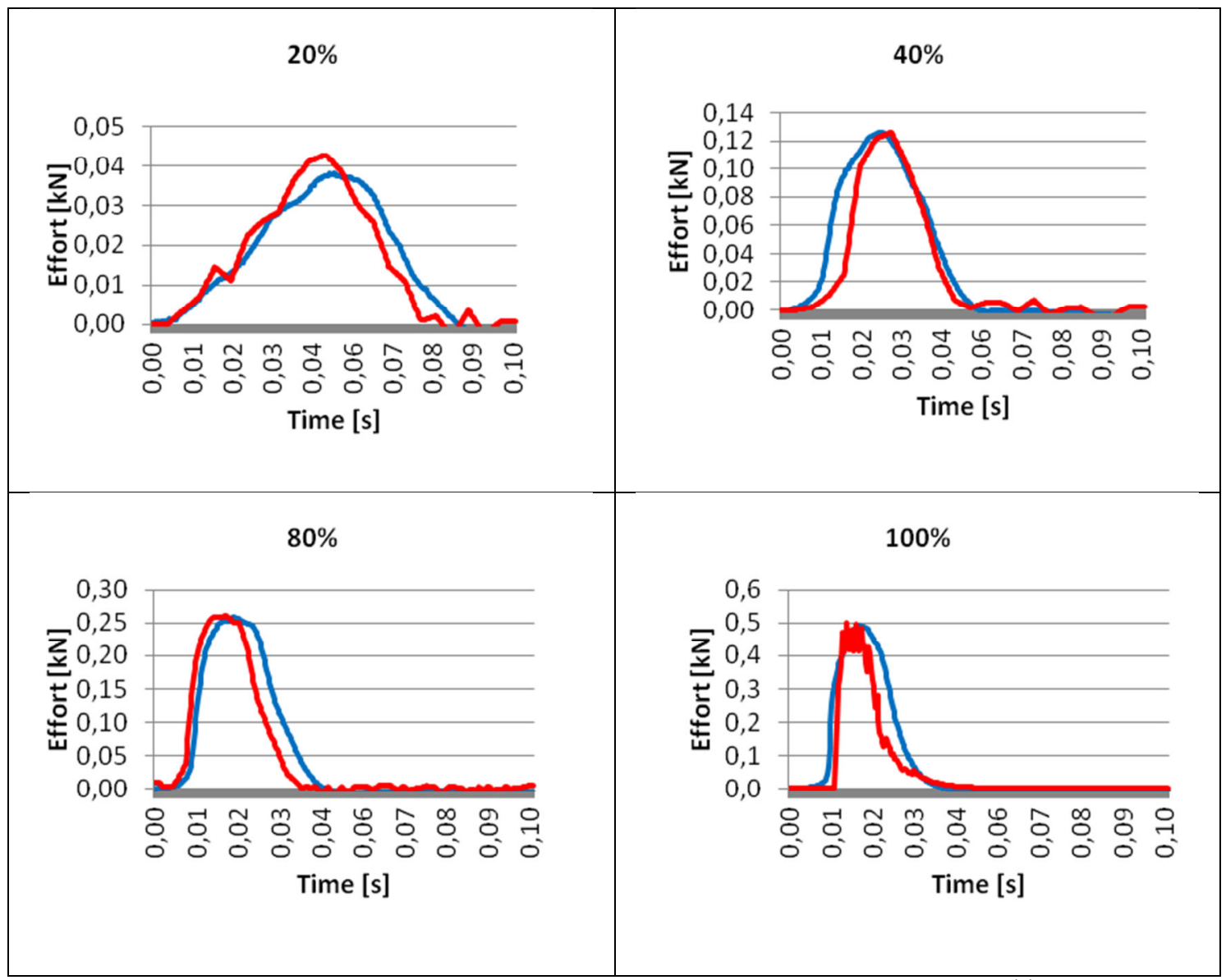

Figure 14 Comparison between experimental (blue) and numerical (red) signals $f_{3}(t)$ for the four impacts of $20 \%, 40 \%, 80 \%$ and $100 \%$ of $\mathrm{E}_{\max }$.

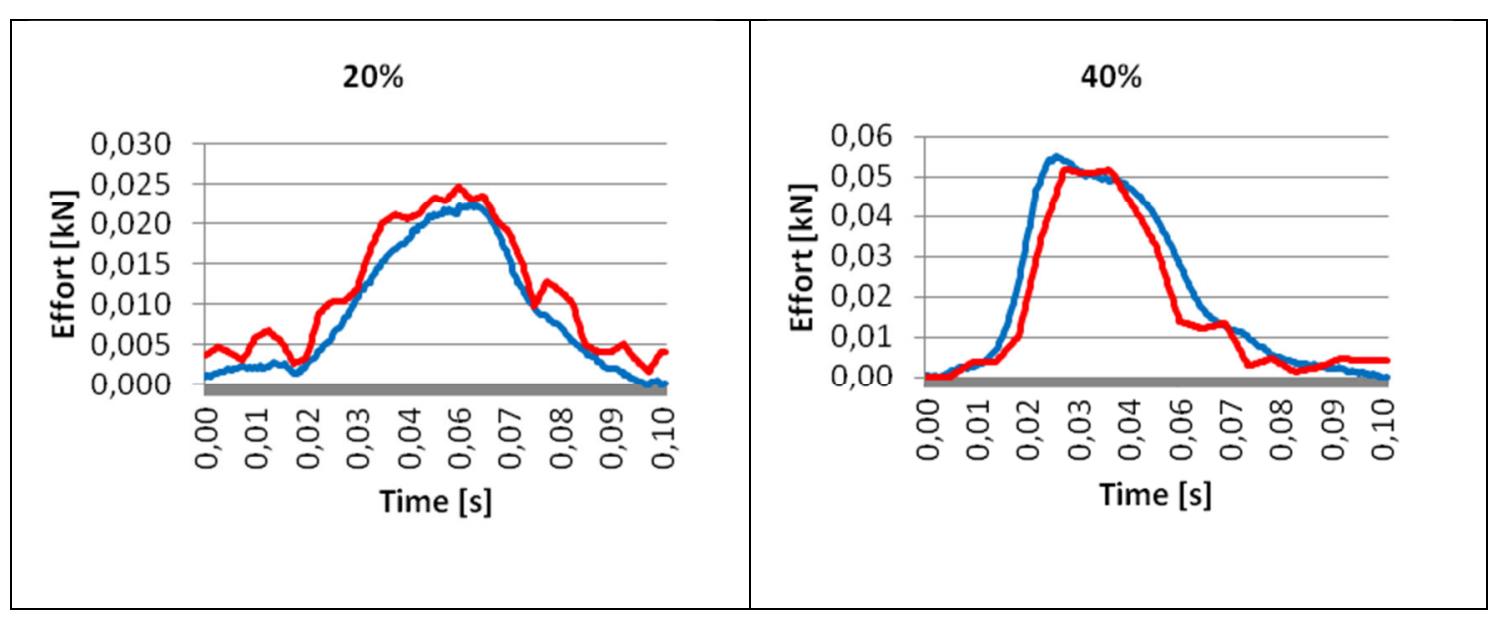




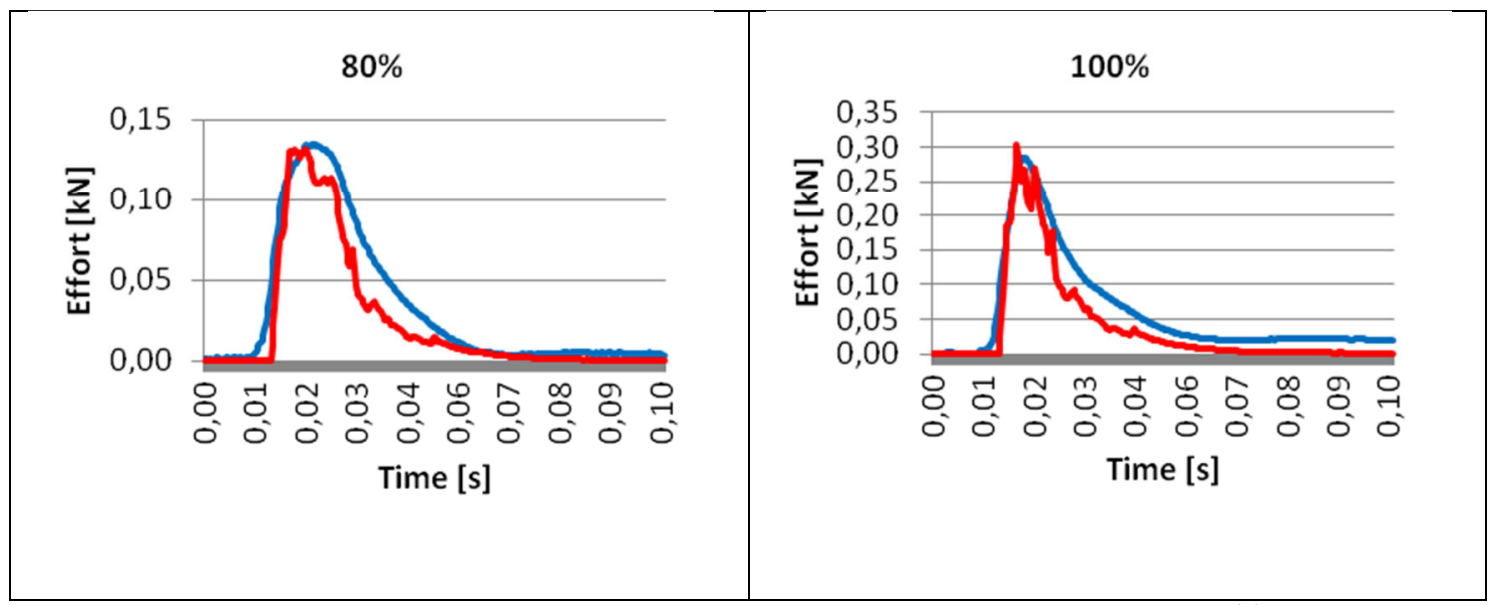

Figure 15 Comparison between experimental (blue) and numerical (red) signals $f_{4}(t)$ for the four impacts of $20 \%, 40 \%, 80 \%$ and $100 \%$ of $\mathrm{E}_{\max }$.

\section{Accelerations}

There are four points where the accelerations were measured: a1, a2, a3 and a4 (Figure 16). The first one corresponds to the steel ball horizontal acceleration and the other points correspond to horizontal acceleration at specific positions for three grains. The acceleration a2 corresponds to a grain located in the back of the gabion, and it has measured the acceleration of the motion toward the boundary of the structure (left picture in Figure 16). The acceleration a3 and a4 correspond to two grains located in the middle of the structure (right picture in Figure 16) and it has measured the acceleration of the motion toward the left and the right of the central gabion respectively. In Figure $17-19$ is shown the comparisons between the experimental and numerical accelerations signals for the grains.



Figure 16 Distribution of the acceleration points. 


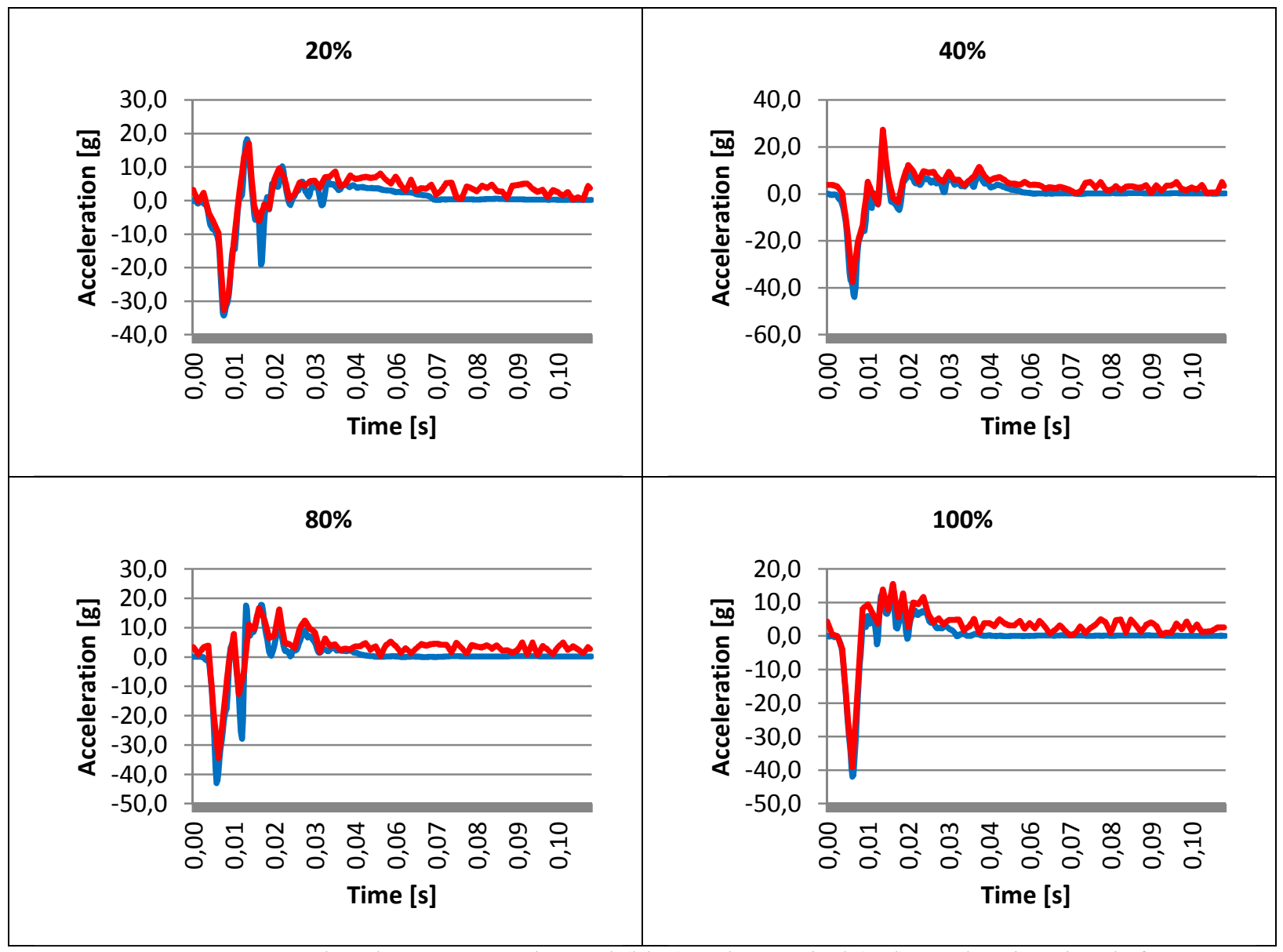

Figure 17 Comparison between experimental (blue) and numerical (red) acceleration signals for the four impacts of $20 \%, 40 \%, 80 \%$ and $100 \%$ of $\mathrm{E}_{\max }$ at point $a 2$.






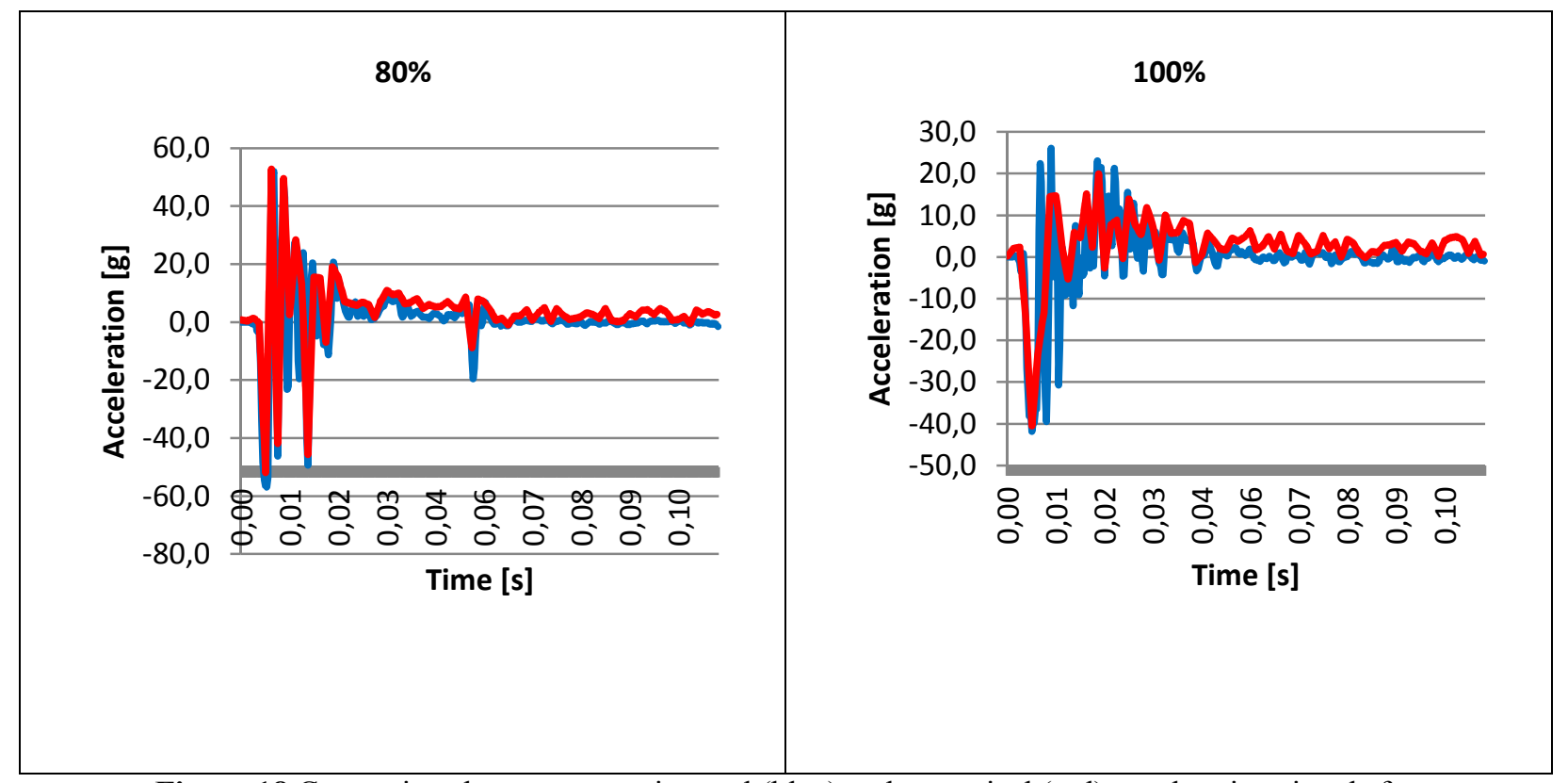

Figure 18 Comparison between experimental (blue) and numerical (red) acceleration signals for the four impacts of $20 \%, 40 \%, 80 \%$ and $100 \%$ of $\mathrm{E}_{\max }$ at point $a 3$.

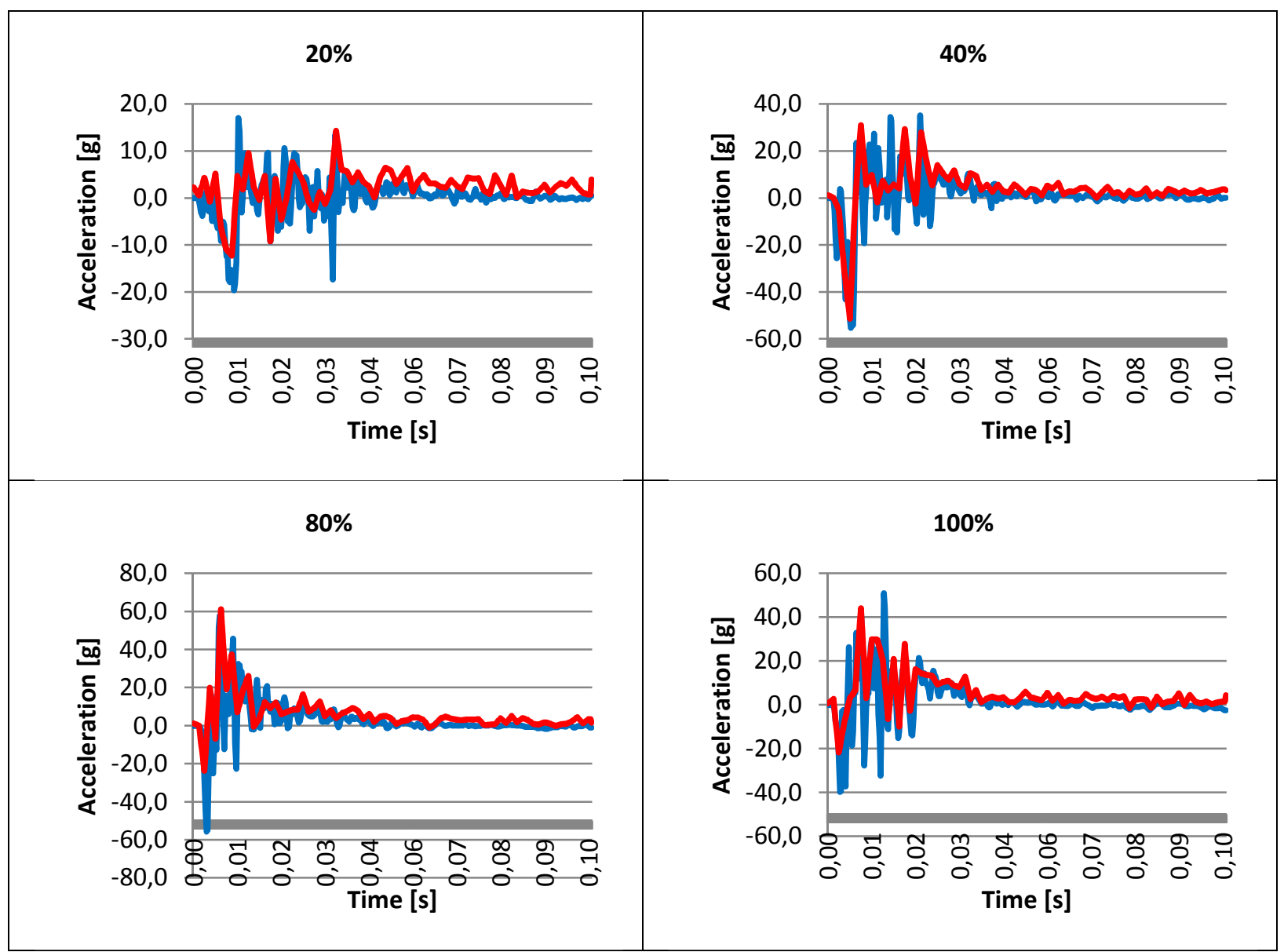

Figure 19 Comparison between experimental (blue) and numerical (red) acceleration signals for the four impacts of $20 \%, 40 \%, 80 \%$ and $100 \%$ of $\mathrm{E}_{\max }$ at point $a 4$.

Concerning the measurements of the steel ball acceleration, the accelerometer could only register the signal peaks for the first three impacts. The problem could be fixed for the last impact only. For this reason, it is possible only obtain the experimental acceleration signal during the impact with $100 \%$ of $E_{\max }$, which is shown in 




Figure 20.

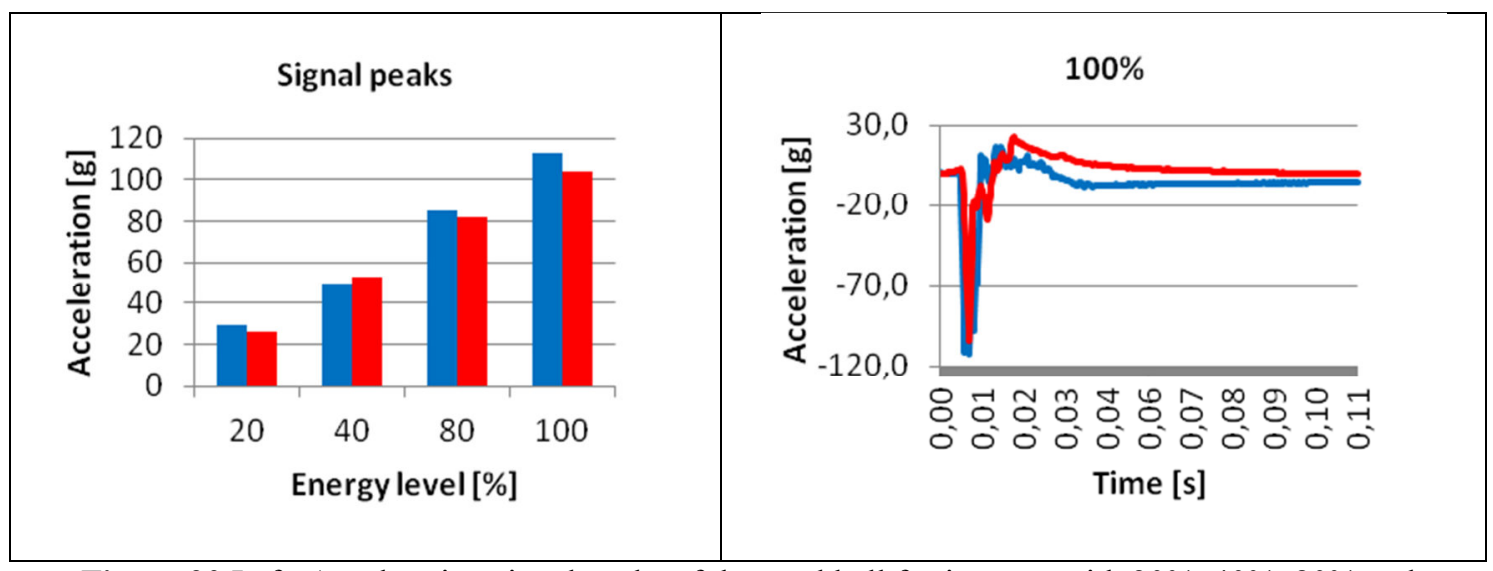

Figure 20 Left: Acceleration signal peaks of the steel ball for impacts with $20 \%, 40 \%, 80 \%$ and $100 \%$ of $E_{\max }$. Right: Comparison between experimental (blue) and numerical (red) acceleration signals for the four impacts of $20 \%, 40 \%, 80 \%$ and $100 \%$ of $\mathrm{E}_{\max }$ at point $\mathrm{a} 1$.

\section{Displacements}

The displacement sensors measured the maximal displacement of the blocks belonging to the backside of the gabion - wall during each impact. In the numerical simulation, this displacement is computed by comparing the positions of the corresponding grains in the backside of the gabion wall to their positions before the first impact. In Figure 21 is shown the comparison between maximum displacements for the four impacts with different energy levels.

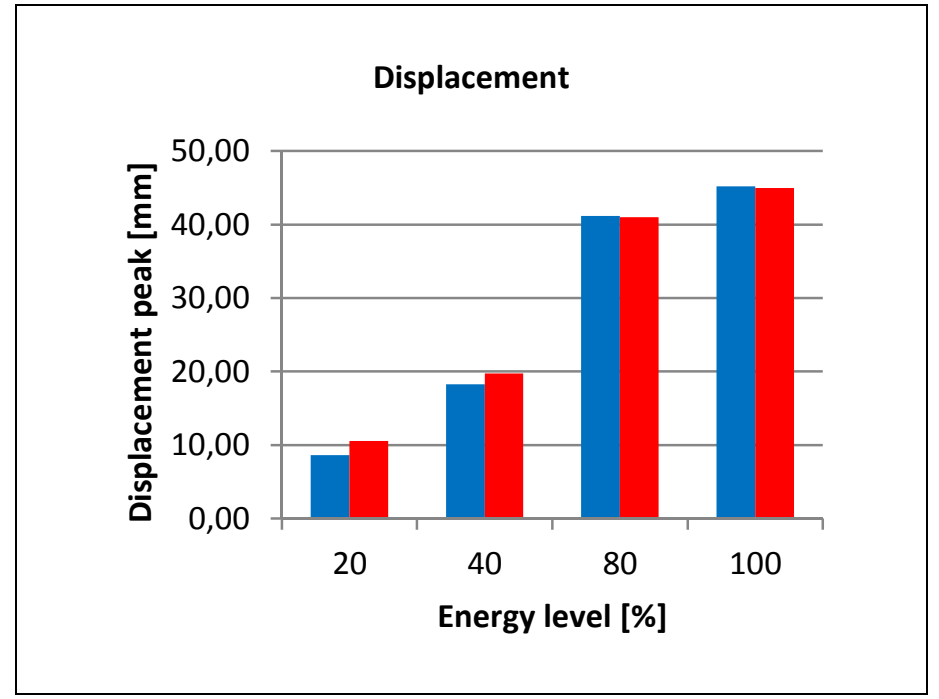

Figure 21 Comparison between experimental (blue) and numerical (red) maximum displacements for the four impacts of $20 \%, 40 \%, 80 \%$ and $100 \%$ of $\mathrm{E}_{\max }$. 


\section{Conclusions}

The primary goal of this study was to measure the shock absorbing capacity of a sandwich structure and to test the ability of the $\mathrm{A}-\mathrm{CD}^{2}$ method to compute impacts in such structures.

The accuracy of the numerical results, compared to the experimental measurements, validates the use of this method for impact on granular layers. Indeed, the numerical and experimental curves have matching shapes and amplitude, although minor differences can be noticed.

Figures $12-15$ and Figures $17-21$ show that the numerical signal is less close to the experimental one for the first impact, than it is for the next impacts. The mean reason for this difference is due to the compaction. The preparation of the gabions requires a compaction process numerically modeled by a succession of uniform impacts. The compaction of the gabions thus obtained is different from the compaction of the real gabions. Some rearrangements between the grains are still possible and occur during the first computed impact.

In addition, let's mention that the experimental signals do not fit as well for acceleration as they do for forces and the displacements. It is also obvious that the acceleration signals (both experimental and numerical) are much more erratic than the others. To understand this difference, one must consider that the acceleration signals have been measured inside the gabions (Figure 4) whereas forces and displacements have been measured at the boundary of the gabions. Force chains in granular media are discontinuous in time and space [6] during its evolution, such that one single grain of the media has strongly non - smooth evolution. For this reason, one can't hope to obtain perfectly matching experimental and numerical signals, but can be satisfied to have obtained signals with similar trends and amplitudes.

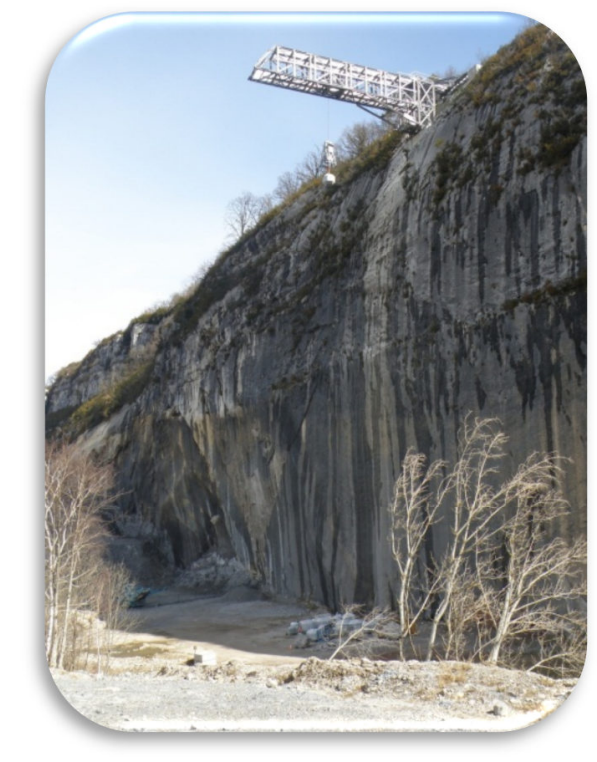

Figure 22 IFSTTAR's rock fall station in Montagnole.

The study of impacts in a sandwich structure, supported by ANR project REMPARE [22] has shown promising results for further studies of the shock absorbing capacity of granular structures. As the pendulum impact facility used for this study does not enable impacts with energies higher than $10[\mathrm{~kJ}$, coming impact experiments will be carried out at IFSTTAR's rock fall station in Montagnole (Figure 22). These experiments, scheduled fall 2012, will consist in vertical impacts of $500[\mathrm{~kJ}]$ to $3000[\mathrm{~kJ}]$ impact energy.

As the $\mathrm{A}-\mathrm{CD}^{2}$ method has shown his efficiency for the numerical simulation of impacts in granular structures in this study; it will also be used to simulate the coming experiences. The computational performances will therefore have to be improved in order to simulate impacts in larger granular layers or in similar layers with smaller (thus more numerous) grains. For this purpose, the implementation of high performance computational techniques in the scope of the A$\mathrm{CD}^{2}$ method is investigated at IFSTTAR and Universidad Técnica Federico Santa María with the support of the project 11R095 "Chutes de blocs et éboulements rocheux" of IFSTTAR.

As the experiments described in this paper have been carried out with impact energies lower than $10[\mathrm{~kJ}]$, the limestone blocks have not been significantly cracked or damaged and we have ignored these aspects in our mechanical model. As the coming experiments will be carried out with much 
higher impact energies, the need for adding a cracking model for the grains will be investigated when modeling them. 


\section{References}

1. Dal Pont S., Dimnet E., A theory for multiple collisions of rigid solids and numerical simulation of granular flow, International Journal of Solids and Structures, 43, pp. $6100-6114,2006$

2. Fletcher Q., Hermann L.R., Elastic foundation representation of continuum, Journal of Engineering Mechanics, pp. 95 - 100, 1971

3. Dal Pont S., Dimnet E., Theoretical approach and numerical simulation of instantaneous collisions in granular media using the $\mathrm{A}-\mathrm{CD}^{2}$ method, Communications in Applied Mathematics and Computational Science, Vol. 3, $\mathrm{N}^{\circ} 1$, pp. $1-2,2008$

4. Jean M., The non - smooth contact dynamic method, Computer Methods in Applied Mechanics and Engineering, 177 (3-4): 235 - 257, 1999

5. Frémond M., Rigid bodies collisions, Physics Letters, pp. 34 - 41, 1995

6. Hunt, G. W., Tordesillas, A., Green, S. C., Shi, J. Y., Force - chain buckling in granular media: a structural mechanics perspective, Philosophical Transactions of the Royal Society A Mathematical Physical and Engineering Sciences, 368 (1910), pp. 249 - 262, 2010

7. Shiu, W., Donzé, F. V., Daudeville, L., Penetration prediction of missiles with different nose shapes by the discrete element numerical approach, Computers and Structures, doi:10.1016/j.compstruc.2008.03.003, 2008

8. Jerier, J - F., Imbault, D., Donze, F.V., Doremus, P., A geometry algorithm based on tetrahedral meshes to generate dense polydisperse sphere packing, Granular Matter, doi:10.1007/s10035-0080116-0, 2008

9. Guidelines for soil description, $4^{\text {th }}$ edition, Food and agriculture organization of the United Nations, Rome 2006

10. Nocedal, J., Wright, S., Numerical Optimization, Springer, 1999

11. Ciarlet, P., Introduction to Numerical Linear Algebra and Optimization, Cambridge, 1989

12. Yoshida, H., Recent experimental studies on rock fall control in Japan, Proc. Joint Japan Swiss scientific seminar on impact by rock falls and design of protection structures, Kanazawa, Japan, pp. 69 - 78, 1999

13. Heymann, A., Lambert, S., Gotteland, P., Collombet, M., Douaillat, M., Expérimentations grandeur réelle sur merlons de protection contre les chutes de blocs rocheux, Journées Nationales de Géotechnique et de Géologie, Grenoble, 2010

14. Lambert, S., Heymann, A., Gotteland, P., Douaillat, M., Haza - Rozier, E., Vinceslas, G., Comparaison expérimentale semi - vraie grandeur du comportement de trios structures pare blocs, Journées Nationales de Géotechnique et de Géologie, Grenoble, 2010

15. Dimnet, E., Evolution of systems of multiples solids, International Conference on non mooth/non - convex mechanics with applications in the engineering, Aristotle University of Thessaloniki, Athens, 2002

16. Dimnet, E., Collisions of rigid bodies, deformable bodies and fluids, $2^{\text {nd }}$ MIT Conference on Computational Fluid and Solid Mechanics, Boston, 2003

17. Dimnet, E.,Frémond, M., Gormaz, R., San Martin, J., Novel approaches in civil engineering collisions involving solids and fluids, Springer Verlag Heidelberg, 2001

18. Moreau, J., Fonctionnelles convexes, Séminaire sur les équations aux dérivées partielles, Collège de France, Paris, 1966 
19. Pfeiffer, F, Non - smooth mechanics, A Theme Issue, Philosophical Transactions of the Royal Society, 359 (1789), 2001

20. Lambert, S., Comportement mécanique de géocellules - application aux constituants de merlons pare - blocs cellulaires, Thése de doctorat, Université Joseph Fourier, Grenoble, 2007

21. Dimnet, E., Mouvement et collisions de solides rigides ou déformables, Thèse de doctorat, École Natinale des Ponts et Chaussées, 2002

22. Haza - Rozier, E., Project ANR REMPARe - Station d'impact pendulaire du CER - Merlons pare - blocs, Rapport de fin de projet, 2010

\section{Acknowledgements}

This research was support by projects ANR REMPARe, IFSTTAR's OR 11R095 research project, and by the Chilean grant CCTVal FB/24GH/10. Partial support was also received from DGIP grant from Universidad Técnica Federico Santa María and MECESUP Project FSM - 0707. 